\title{
A Resilient Multi-factor Framework for Low Carbon Cities: An International Perspective
}

\author{
Yin Zeng, Shuliang Li, Liangru Deng, Shuoyue Feng
}

\begin{abstract}
The roles of cities in low carbon transition and sustainable development strategies have never been so important. This paper focuses on the transition, while considering the current situations of city carbon emissions in the world. The management practice of city low carbon transformation is analyzed and expounded. We then discuss the low carbon resilience of cities, and establish a mathematical and logical model. The paper illustrates relevant scenarios of the measurement factors, and the meanings of the resilience coefficient. Furthermore, we propose and refine a framework for analyzing the resilience, in combination with emission accounting tools and various aspects of city development.
\end{abstract}

Index Terms-Low carbon city, low carbon resilience, low carbon management, low carbon economy, carbon dioxide emission.

\section{INTRODUCTION}

3 percent of the land area produces about 70 percent of the total carbon emissions of human activities. Cities account for about half of the world's whole population. With the development across the world, the city population will increase to 6.5 billion by 2050, and the problem of city carbon emissions will be become more and more serious. The cities in developing countries and underdeveloped countries will be faced by the challenge of higher carbon emission growth. The cities in developed countries will be subject to international carbon emission reduction targets. Moreover, the global climate problem is not only closely related to the economic development of cities, but also has negative impacts on ecological environments, transportation and energy structure. Under the critical limit of $2^{\circ} \mathrm{C}$, city development is bound to move towards low-carbon transformation, and thus carbon reduction measures should be taken systematically from all aspects of the city.

Nevertheless, the behavior of cities is influenced by the system of resource endowment, energy structure, economic development and other factors. Previous research effort on linking sustainability with low carbon resilience is not adequate. Not enough attention has been paid to the incorporation of emission accounting. There is also a lack of integration of government departments, enterprises and

Manuscript received May 2018; revised December 13, 2018

Yin Zeng is with School of Management, Sichuan University of Science and Engineering, Zigong, China (e-mail: zengyin@live.cn).

Shuliang Li is with the University of Westminster, London, England, UK, and Southwest Jiaotong University, China (e-mail: s.li@westminster.ac.uk).

Liangru Deng is with Chengdu Seqdata Technology Co. Ltd., China (e-mail: liangrudeng@163.com).

Shuoyue Feng is with Almanac of China's Economy Press, Beijing, China (e-mail: shuoyue1999@hotmail.com). citizens for carbon emission reduction. Therefore, more accurate, effective, holistic and comprehensive methods are needed to clarify the city carbon management idea.

This paper will expound the inner mechanism of the city's various fields and carbon emissions in terms of low-carbon resilience, and refine the corresponding analytical framework, in order to provide valuable reference for the low-carbon transformation.

\section{Current Situations of City CARbon EMissions AND MANAGEMENT}

\section{A. Carbon Emissions of Cities}

Cities are the main body of a national government to implement the framework mechanism of international climate change, and the accurate and effective calculation of a city's carbon emission is the primary task for a country to set the carbon emission reduction targets. International organizations, institutions, and governments at all levels have constantly been trying to regulate appropriate detailed standards for measuring the city level of carbon emissions. For example, International Council for Local Environmental Initiatives (ICLEI) formulated the International Local Government Greenhouse Gas Emissions Analysis Protocol (community section) in 2009. The International Standard for Determining Greenhouse Gas Emissions for Cities was jointly compiled by the World Bank, the United Nations Environment Programme (UNEP), and UN-HABITAT in 2010. On the basis of the draft, the World Resources Institute, C40 Cities Climate Leadership Group and ICLEI - Local Governments for Sustainability (ICLEI) jointly compiled Global Protocol for Community - Scale Greenhouse Gas Emission Inventories in 2013, which become the standard for city carbon emission accounting.

CDP (Carbon Disclosure Project), as a non-profit organization with high credibility, carries out the most comprehensive climate disclosure for cities and enterprises every year. 572 cities worldwide by 2017, have participated in the CDP city climate disclosure project. The disclosed data helps a city learn more about the scale of its carbon emissions and the segmentation data in various fields, so as to better grasp the carbon management strategy. In addition, it can provide real cases for other cities that do not disclose their carbon emissions. According to the disclosure in the 229 cities as shown in Fig. 1, the active participating cities are mainly located in North America, Europe and other developed countries, including some in southeast Asia. Among them, the carbon emission scale of cities in North American and Southeast Asian is relatively high. However, the fact that carbon emissions are larger, broader and more 
nebulous in scale 3 has not yet been counted, making a city's carbon footprint less tangible. The normal operation of a city needs all kinds of contact with many others, such as transportation, the upstream and downstream activities outside the city boundaries. Thus, there is the need for more in-depth carbon accounting measurement methods and effective tools.

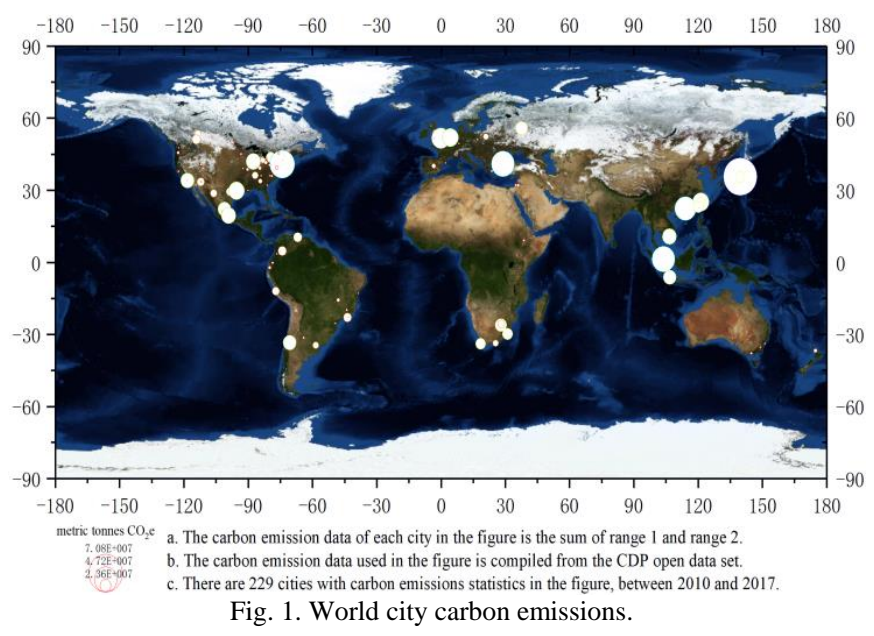

\section{B. City Carbon Management}

The United Nations NAZCA Tracking Climate Action (NAZCA Tracking Climate Action) statistics show that 2508 cities worldwide have revealed their plans of action to reduce emissions. In China, however, only Anshan, Jinan and Shenzhen make their carbon emission reduction targets to the public. Chinese cities are relatively less transparent about carbon management, and thus need to improve their confidence in their carbon management capability and carbon information disclosure. Nonetheless, there are huge differences in the levels of low-carbon development across different cities. If a city lacks a clear understanding of self-emissions, and its low carbon advantage is insufficient, then it is easy to lose confidence in the development and, therefore, may form a vicious circle. This does not conform to the global effort on tackling climate change, and would affect the participation of backward cities in international competition. Nowadays, with the background of low carbon economy globalization, it is inevitable for cities to carry out effective management.

The Global Covenant of Mayors for Climate \& Energy has developed into the largest city climate management organization in the world, actively promoting the low-carbon collaboration across cities, enterprises, regions and citizens, and has achieved remarkable results. By 2017, 362 cities have identified carbon reduction targets (see Fig. 2). In order to attain the goal, each city has formulated the carbon emission reduction management plan, such as increasing the proportion of renewable energy sources (see Fig. 3), adaptive measures, the government operation of carbon emission reduction activities, and communities of reduction. Typical management plans are shown in Table 1. However, relying on isolated action plans is obviously not enough. This cannot systematically integrate carbon emission reduction with the economic and social development of cities, and can make it difficult for carbon emission measures to have a practical effect. Therefore, a resilient mechanism is urgently needed to help cities explore the internal mechanism of development in various fields. It is suggested that more scientific and feasible measures should be drawn up, and the internal links can be observed to consider the relationships between the development and the carbon emissions in various fields [1]-[3].

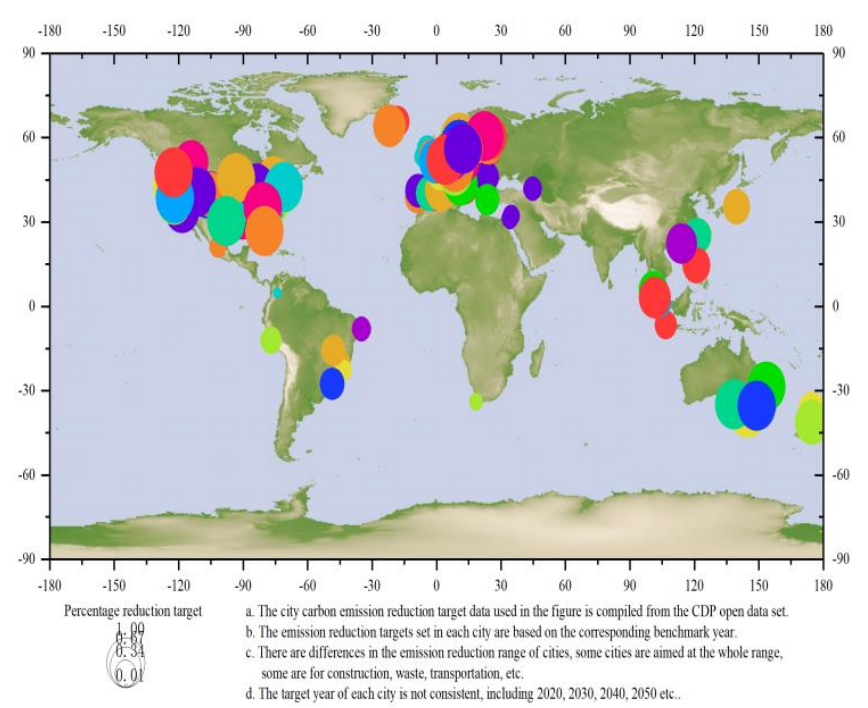

Fig. 2. World city carbon reduction targets.

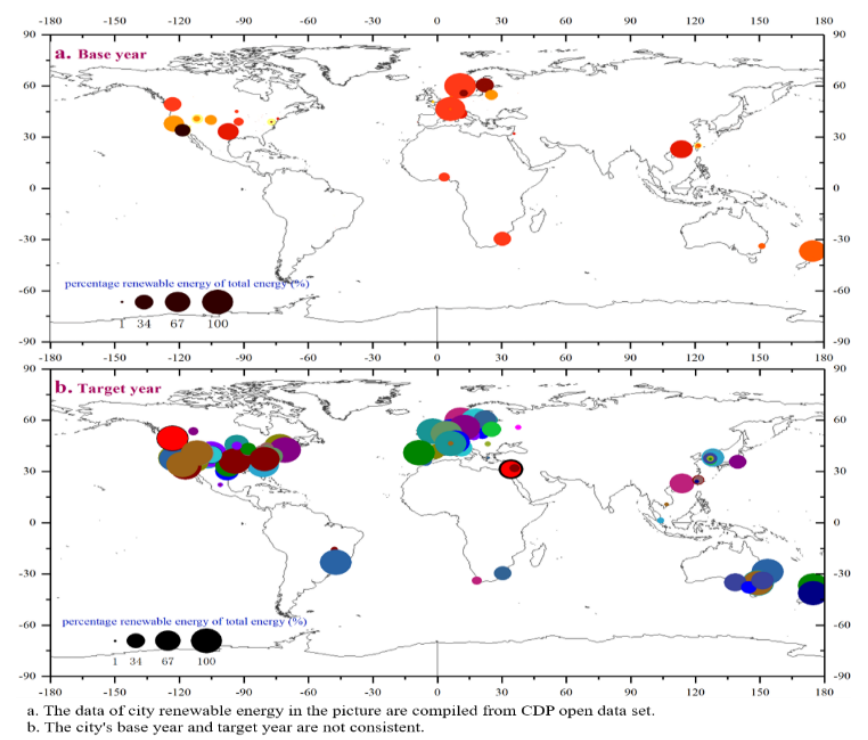

Fig. 3. World city renewable energy development targets.

From the NAZCA disclosure of information, a city government often joins the international climate action to declare its targets, action plan, etc. For instance, London joined the 'C40 Cities Clean Bus Declaration', 'Carbon Neutral Cities Alliance', 'Compact of Mayors', 'the Covenant of Mayors', 'Global Energy Efficiency Accelerator Platform'. City carbon emission management is complicated, with many aspects involved. We should not just rely on the government of a city, because a large portion of the source of carbon emissions is not within the direct jurisdiction of the government departments [4]-[6]. According to CDP's statistics, only $3 \%$ of the carbon emissions were produced by city government departments worldwide. Buildings, personal travel and other aspects are the main sources. Hence, the carbon emission management must infiltrate into the enterprise and the citizen level for joint collaboration. 
TABLE I: TYPICAL CITY CARBON EMISSION REDUCTION ACTION PLANS

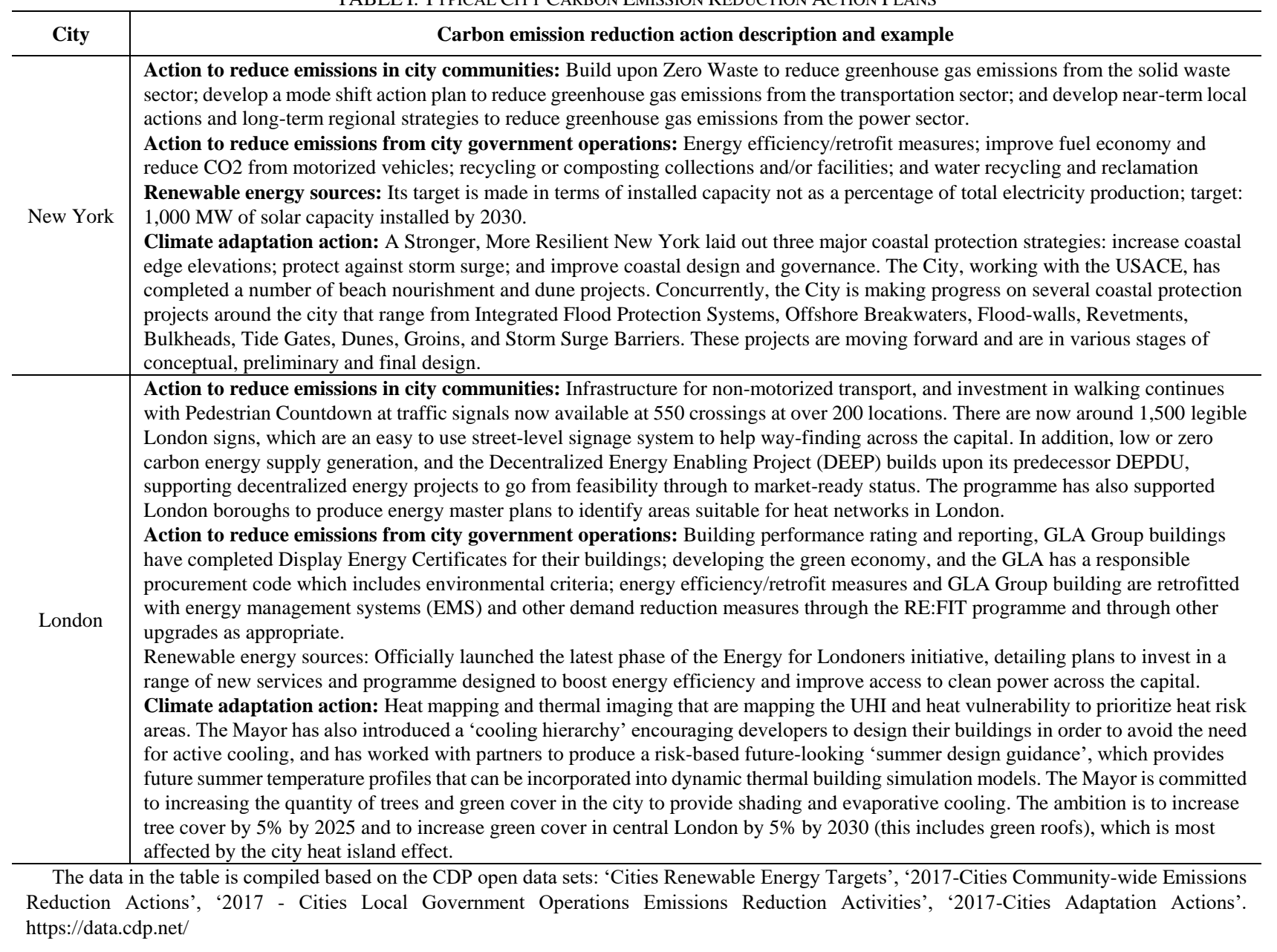

\section{A FrAMEWORK FOR CITY LOW CARBON RESILIENCE}

\section{A. City Low Carbon Resilience}

The concept of resilient cities was first proposed by renowned ecologist Holling in 1973 [7]. In view of the impact of carbon emissions on sustainable development, researchers have explored the resilient law of carbon emissions from different perspectives. Zhuang [8] analyzed the path of China's low carbon transformation based on the city development. Stern [9] used the environmental Kuznets curve to analyze income resilience. Li et al. [10] investigated the carbon emission resilience of industrial clusters. Isaksen et al. [11] analyzed Norway's carbon emissions with the resilience of expenditure carbon footprint. Relevant findings include: the carbon emission characteristics of residents [12], carbon emission resilience of industrial energy consumption [13], the resilience of construction land [14], and agricultural carbon emission resilience [15]. It can be seen that the development of city areas and carbon emissions have complex interwoven internal relationships. It is necessary to clarify the various factors and the resilience to find the direction of low carbon action and the degree of strengths. The low carbon resilience of city elements can be formulated as

$$
\varepsilon_{\mathrm{CO}_{2}}^{i}=\frac{\Delta X_{i} / X_{i}}{\Delta C O_{2}^{i} / \mathrm{CO}_{2}^{i}} \text { or }-\frac{\Delta X_{i} / X_{i}}{\Delta C O_{2}^{i} / \mathrm{CO}_{2}^{i}}
$$

In equation (1), $\varepsilon_{\mathrm{CO}_{2}}^{i}$ stands for the low carbon resilience coefficient of term i, such as water resource, building, greening and consumption, etc.

The factors of a city can be expressed as

$$
X_{i}=f\left(x_{i}^{1}, x_{i}^{2} \cdots x_{i}^{j} \cdots, x_{i}^{n}\right)
$$

In equation (2), $x$ denotes the independent variable of a relevant factor. $X_{i}$ adopts the corresponding field theory to measure various factors. Examples are given as follows. Enterprises can use production functions. And citizens can use consumption functions.

Carbon emissions can be measured by the total amount of emissions, or by the unit strength. This can be represented as

$$
C O_{2}^{i}=\left(E_{o}+\sigma\right) \exp (-\gamma t)+\sigma
$$

In the equation (3), $E_{0}$ is the base of carbon emissions; $s$ is the emission covariate reflecting an increase or decrease of the factor; $g$ is the carbon attenuation coefficient; and $t$ is the length of time relative to the base period, in years.

$$
e_{i}=\frac{C O_{2}}{Y}=\frac{\sum_{i=1}^{n} Y_{i} \cdot e^{i}}{\sum_{i=1}^{n} Y_{i}}
$$




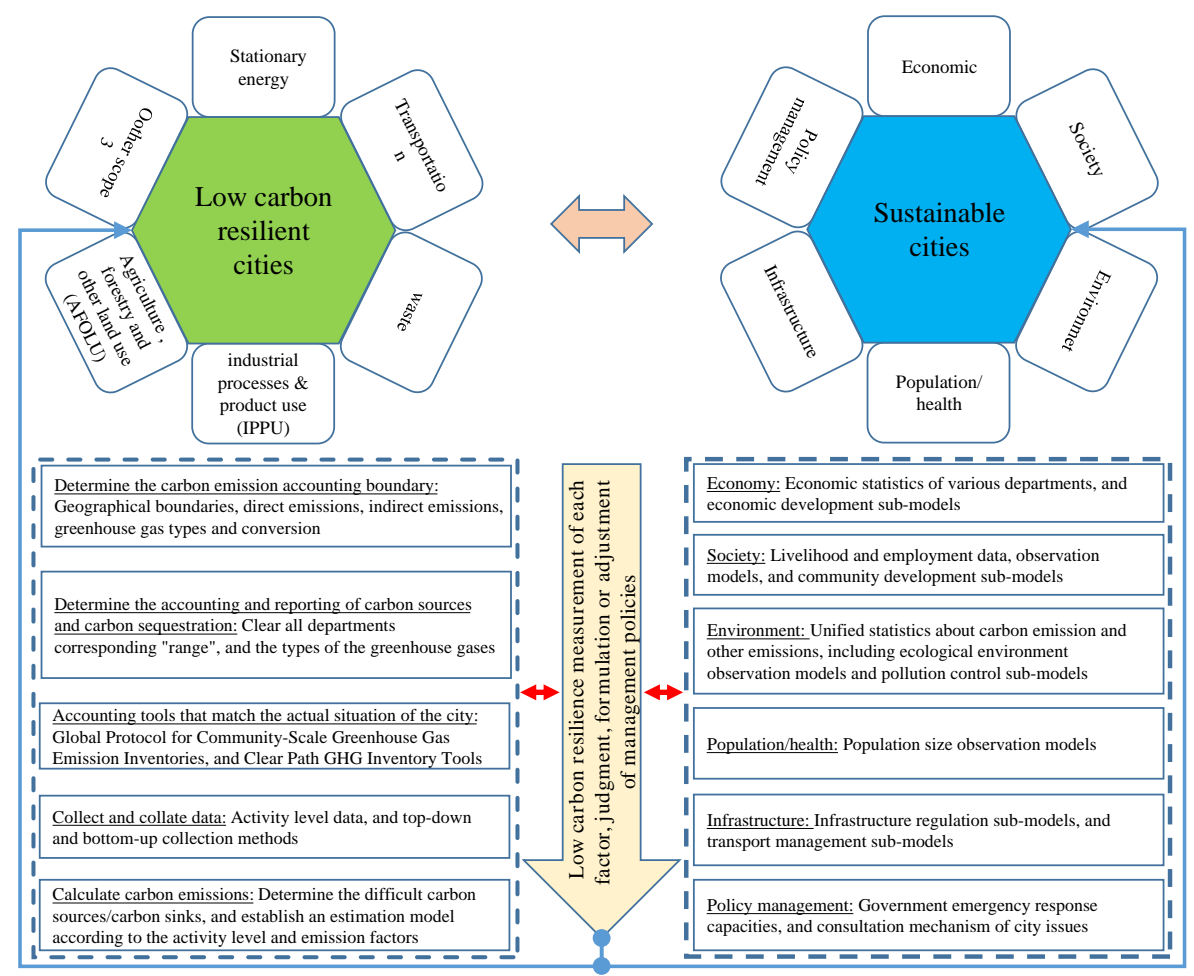

Fig. 4. A framework for analyzing city low carbon resilience.

In the equation (4), $e_{i}$ is the unit carbon emission of the factor of term i; $\mathrm{Y}$ is the total amount of item $\mathrm{i}$; $\mathrm{n}$ denotes the type of emissions; $Y_{\mathrm{i}}$ denotes the total amount of emissions corresponding to type $i ; e^{i}$ is the emission intensity, or the emission factor of type $i$. We have

$$
\begin{aligned}
\Delta C O_{2}= & \Delta e \\
& =\sum_{j=1}^{\infty} \frac{1}{j !}\left[\sum_{i=1}^{n} \Delta Y_{i} \frac{\partial}{\partial \Delta Y_{i}}+\sum_{i=1}^{n} \Delta e^{i} \frac{\partial}{\partial \Delta e^{i}}\right]^{j} e \\
& =\sum_{i=1}^{n}\left(e^{i}-e\right) \Delta a_{i}+\sum_{i=1}^{n} \Delta e^{i} a_{i} \\
& +\sum_{j=2}^{\infty} \frac{1}{j !} \sum_{k=0}^{j} \frac{j !}{(j-k) ! k !}\left[\left(\sum_{i=1}^{n} \Delta Y_{i} \frac{\partial}{\partial Y_{i}}\right)^{j-k}\left(\sum_{i=1}^{n} \Delta e^{i} \frac{\partial}{\partial e^{i}}\right)^{k}\right] e
\end{aligned}
$$

In equation (5), $\Delta Y_{i}$ represents the corresponding carbon emission variation of type $i ; \Delta e^{i}$ denotes the emission intensity or emission factor variation of type $i ; a_{\mathrm{i}}=Y_{i} / Y$ symbolizing the carbon emissions accounted for the proportion of total emissions of type $i ; \Delta a_{i}$ stands for the variation compared with the reference time.

$$
\text { With } \underbrace{\frac{\partial^{k} e}{\partial e_{i} \cdots \partial e^{i_{k}}}}_{k} \equiv 0\left(k \geq 2, i_{i}=1, \cdots, n\right) \text { we get }
$$

$$
\begin{aligned}
& \Delta e=\sum_{i=1}^{n}\left(e^{i}-e\right) \cdot \Delta a_{i}+\sum_{i=1}^{n} \Delta e^{i} \cdot a_{i} \\
&+\sum_{j=2}^{\infty} \frac{1}{j !}\left\{\left[\sum_{i=1}^{n} \Delta Y_{i} \frac{\partial}{\partial Y_{i}}\right]^{j} \cdot e+\frac{j !}{(j-1) !}\left[\left(\sum_{i=1}^{n} \Delta Y_{i} \frac{\partial}{\partial Y_{i}}\right)^{j-1} \cdot\left(\sum_{i=1}^{n} \Delta e^{i} \frac{\partial}{\partial e^{i}}\right)\right] \cdot e\right\} \\
&= \sum_{i=1}^{n}\left(e^{i}-e\right) \cdot \Delta a_{i}+\sum_{i=1}^{n} \Delta e^{i} \cdot a_{i} \\
&+\sum_{j=2}^{\infty} \frac{1}{j !}\{(-1)^{j-1}(j-1) ! \underbrace{\sum_{i=1}^{n} \cdots \sum_{i_{j}=1}^{n}}_{j} \underbrace{\Delta a_{i_{1}} \cdots \Delta a_{i_{i}}}_{j}[\underbrace{\left(e^{i_{i}}+\cdots+e^{i_{j}}\right)}_{j}-j \cdot e]\}
\end{aligned}
$$

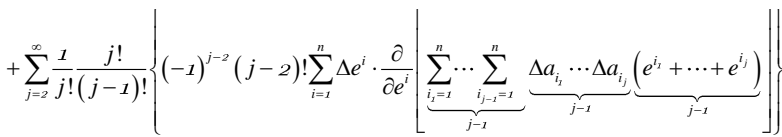

$$
\begin{aligned}
& +\sum_{j=2}^{\infty} \frac{1}{j !} \frac{j !}{j-1}\{!(-1)^{j-2}(j-2) ! \sum_{i=1}^{n} \Delta e^{i} \underbrace{\sum_{i=1}^{n} \cdots}_{i=1} \sum_{j=1}^{n} \underbrace{\Delta a_{i} \cdots \Delta a_{i, j}}_{j=1}\left[-(j-1) \cdot a_{i}\right]\} \\
& =\sum_{i=1}^{n}\left(e^{i}-e\right) \cdot \Delta a_{i}+\sum_{i=1}^{n} \Delta e^{i} \cdot a_{i}+\sum_{i=1}^{n} \sum_{j=2}^{\infty}(-1)^{j-1} \underbrace{\sum_{j=1}^{e_{i}+\cdots+e^{i_{j}}}}_{\sum_{i=1}^{n} \cdots \sum_{j=1}^{n}}-e) \underbrace{\Delta a_{i} \cdots \Delta a_{i_{i}}}_{j}
\end{aligned}
$$

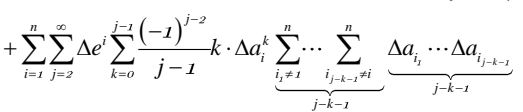

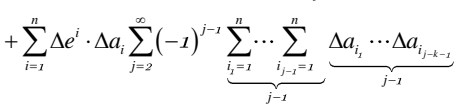

$$
\begin{aligned}
& =\sum_{i=1}^{n}\left(e^{i}-e\right) \sum_{j=1}^{\infty}(-1)^{j-1} \cdot \Delta a_{i}^{j}+\sum_{i=1}^{n} \Delta e^{i} \cdot a_{i}+\sum_{i=1}^{n} \Delta e^{i}\left(a_{i}-1\right) \sum_{j=2}^{\infty}(-1)^{j-1} \cdot \Delta a_{i}^{j-1}+\Delta e_{r}
\end{aligned}
$$

Based upon the above method, the low carbon resilience of city factors can be calculated effectively. And the resilience relationship between relevant factors and the carbon emissions can be determined (see Table II). However, it can be seen, from the accounting boundary, that the areas of city development are deeply permeated with the problems of carbon emissions.

\begin{tabular}{c|l}
\multicolumn{2}{c}{ TABLE II: THE LOW CARBON RESILIENCE COEFFICIENT } \\
\hline$\varepsilon_{\mathrm{CO}_{2}}^{i}$ & \multicolumn{1}{c}{ Description } \\
\hline$\varepsilon_{\mathrm{CO}_{2}}^{i}=O$ & $\begin{array}{l}\text { The } i \text { th factor of low carbon is } \\
\text { completely not resilient. }\end{array}$ \\
\hline$O<\varepsilon_{\mathrm{CO}_{2}}^{i}<1$ & $\begin{array}{l}\text { The } i \text { th factor of low carbon is not } \\
\text { resilient }\end{array}$ \\
\hline$\varepsilon_{\mathrm{CO}_{2}}^{i}=1$ & $\begin{array}{l}\text { The } i \text { th factor of low carbon is unit } \\
\text { resilient }\end{array}$ \\
\hline $1<\varepsilon_{\mathrm{CO}_{2}}^{i}<\infty$ & $\begin{array}{l}\text { The } i \text { th factor of low carbon is } \\
\text { resilient. }\end{array}$ \\
\hline
\end{tabular}




\section{B. The Resilient Framework}

The development of resilient cities can certainly help combat climate change. Therefore, making right decisions in practice to reduce emissions is vitally important. For example, by measuring low carbon resilience, carbon sensitive factors and carbon inert factors can be identified. And this then help decision-makers decide whether to formulate a defensive or aggressive strategy. A framework for analyzing the resilience is illustrated in Fig. 4. It can provide a systematic reference for management.

\section{CONCLUSION}

This paper has been sought to develop a resilient multi-factor framework for low carbon cities. On the basis of compiling relevant data and mathematical modeling work, we have proposed a method and conceptual framework for analyzing the internal mechanism of city development factors and carbon emissions. This paper can deliver the following values.

(1) To improve the convenience and pertinence of management by integrating city carbon emission inventory tools with sustainable city development, and covering carbon sources, carbon sinks and city development factors.

(2) To improve the comparability of cities and then find the improvements on urban competitiveness based on the relevant data sets.

(3) To assist a city in: optimizing various resources; improving its carbon emission efficiency; and forming a cooperative mechanism with others.

(4) To help a city improve its ability in: coping with climate disasters; formulating effective low carbon strategies; and improving the development resilience.

\section{ACKNOWLEDGMENTS}

The authors would like to acknowledge the support of Chengdu Soft Science Project about Research on the Mechanism Innovation of the National Carbon Market (Chengdu) Center Capacity Building under the Perspective of Enterprise Carbon Assets (No. 2016-RK00-00076-ZF), and strategies on low carbon Chengdu city development from a resilience perspective (No. 2017-RK00-00132-ZF), the Sichuan 100-Talent Scheme award, and the University of Westminster staff research allowances.

\section{REFERENCES}

[1] M. Jong, S. Joss, and D. Schraven, "Sustainable-smart-resilient-low carbon-eco-knowledge cities; Making sense of a multitude of concepts promoting sustainable urbanization," Journal of Cleaner Production, vol. 109, pp. 25-38, Dec. 2015.

[2] P. Romero-Lankao and D. Dodman, "Cities in transition: Transforming urban centers from hotbeds of GHG emissions and vulnerability to seedbeds of sustainability and resilience: Introduction and editorial overview," Current Opinion in Environmental Sustainability, vol. 3, no. 3, pp. 113-120, May 2011.

[3] Y. Jabareen, "Planning the resilient city: Concepts and strategies for coping with climate change and environmental risk," Cities, vol. 31, no. 2, pp. 220-229, Apr. 2013.

[4] P. Zhao and B. Lu, "Managing urban growth to reduce motorised travel in Beijing: One method of creating a low-carbon city," Journal of
Environmental Planning \& Management, vol. 54, no. 7, pp. 959-977, Jun. 2011.

[5] Y. Wang, Q. Song, and J. He, "Developing low-carbon cities through pilots," Climate Policy, vo1.15, no.1, pp. 81-103, Jun. 2015.

[6] S. Tan, J. Yang, and J. Yan, "A holistic low carbon city indicator framework for sustainable development," Applied Energy, vol. 185, pp. 1919-1930, Jan. 2017.

[7] C. S. Holling, "Resilience and stability of ecological systems," Annual Review of Ecology \& Systematics, vol. 4, no. 4, pp. 1-23, 1973.

[8] G. Zhuang, "How will China move towards becoming a low carbon economy?" China \& World Economy, vol. 16, no. 3, pp. 93-105, 2010.

[9] D. I. Stern, "Between estimates of the emissions-income elasticity 2 , , Ecological Economics, vol. 69, no. 11, pp. 2173-2182, Sept. 2011.

[10] J. Li, Q. S. Wang, and J. H. Zhang, "The study of elastic decoupling and countermeasure of regional industrial clusters carbon emissions," Soft Science, vol. 26, no. 7, pp. 70-74, Jul. 2012.

[11] T. M. L. A. Elisabeth and P. A. Narbel, "A carbon footprint proportional to expenditure - A case for Norway?" Ecological Economics, vol. 131, pp. 152-165, Jan. 2017.

[12] Z. Li, G. Li, and Z. Hu, "Xi'an household carbon emission characteristics (in Chinese)," Resources Science, vol. 39, no. 7, pp. 1394-1404, July 2017.

[13] X. Zhou et al., "A comparative study on decoupling relationship and influence factors between China's regional economic development and industrial energy-related carbon emissions," Journal of Cleaner Production, vol. 142, pp. 783-800, Jan. 2017.

[14] L. Zhang et al., "Measurement and trend analysis of carbon emissions from construction land changes in Anhui in the recent 15 years - Based on STIRPAT model," Acta Scientiae Circumstantiae, vol. 33, no. 3, pp. 950-958, March 2013.

[15] Y. Tian et al., "Agricultural carbon emissions in China: calculation, spatial-temporal comparison and decoupling effects," Resources Science, vol. 34, no. 11, pp. 2097-2105, Nov. 2012.

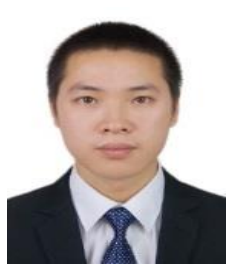

Yin Zeng received the $\mathrm{Ph} . \mathrm{D}$. in management science and engineering from Southest Jiaotong University, Chengdu, Sichuan, China. He worked for School of Management, Sichuan University of Science \& Engineering, Zigong, China as senior lecturer. He has published several papers in various academic journals. His research interests have included city low-carbon strategies, modeling and simulation of carbon assets, carbon intangible assets, carbon markets and policies.

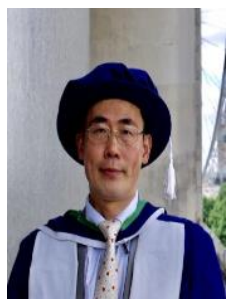

Shuliang $\mathbf{~ L i}$ is a reader (equivalent to a full professor post in North America) at the University of Westminster, London, England, UK. He acted as BIM\&O departmental Research Leader from January 2010 to July 2013. Prof. Li is Sichuan 100-Talent Scheme Visiting Senior Professor at the School of Economic \& Management, Southwest Jiaotong University, China, for research collaboration purposes. He is also an overseas expert for China Development Research Centre. Prof. Li is a life fellow of the British Computer Society (FBCS).

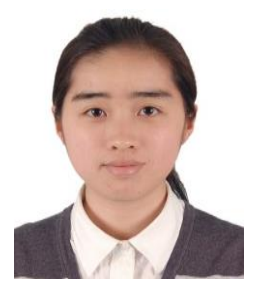

Liangru Deng received her master's degree in public administration from Southest Jiaotong University, Chengdu, Sichuan, China. She worked for Chengdu Seqdata Technology Co. Ltd., China, as Product R \& $\mathrm{D}$ Manager. Her research interests have included the carbon emission, carbon trading modules, carbon trading policy.

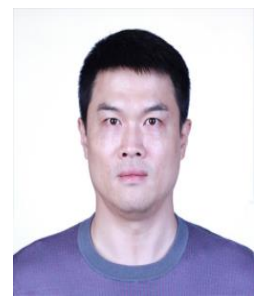

Shuoyue Feng received his Master's degree from the University of Westminster, UK, and currently works at Almanac of China's Economy Press, Beijing, China. 